\title{
Simplified Step-Path method for rock slopes
}

\author{
NRP Baczynski Prime Geotechnics Pty Ltd, Australia
}

\begin{abstract}
Strength of most rock masses is anisotropic. This means that strength is often not uniform in all directions but depends on layering and structural fabric of the rocks. Three components of strength are rock mass, geological defects and intact rock or rock mass 'bridges' between defects. The Hoek-Brown criterion applies to those segments of failure path that are not co-aligned with dominant defect orientations. Conversely, the Hoek-Brown criterion is less representative where the failure path is co-aligned with such fabric. In the latter case, strength is better estimated by the Step-Path method. This approach requires slope face mapping data for several input parameters; drill core does not provide the necessary data. Conventional Step-Path methods use Monte-Carlo simulation of large numbers (>10,000) of paths (Baczynski 2000). Any statistical model (normal, lognormal, exponential) can be considered for input parameters; many are lognormally distributed. A less rigorous Simplified Step-Path method is described in this paper. However, this approach has a limitation; statistical variability for all inputs is approximated by normal distributions. The Rosenblueth method of statistical moments, and Sampling Theory, are used to develop statistical strength models for any user-nominated Step-Path traverse length. Analysis is Excel spreadsheet based. Case study examples are presented. Step-Path computed strength may be 30 to $45 \%$ less than Hoek-Brown values. This strength reduction significantly decreases Factors of Safety and increases stability risks for rock slopes.
\end{abstract}

\section{Introduction}

The strength of some intact rocks and most rock masses is anisotropic rather than isotropic. This means that strength is often not uniform in all directions but depends on layering and structural fabric of the rocks. Rock masses exhibit directional strength due to co-alignment of some geological defect sets with specific directions of shearing. The Step-Path method provides a statistically-based approach for estimating shear strength along defect-controlled failure paths through rock masses (Baczynski 2000, 2016).

The writer acknowledges that the Hoek-Brown method (Hoek \& Brown 1980a, 1980b) is the most widely used approach for estimating rock mass strength. This method with its various revisions including the more recent ones for low unconfined compressive strength (UCS) rock masses (Carvalho et al. 2007) has been used for over 35 years. The four inputs to the Hoek-Brown method are intact rock UCS, Geological Strength Index (GSI), which can be determined directly from a rock mass blockiness versus geological defect condition charts or by transformation from Bieniawski (1989) Rock Mass Rating (RMR) index, mi parameter, which describes the shape of the normal-shear strength curve, and disturbance factor $D(0$ to 1$)$. The strength estimate is effectively isotropic because geological defect orientation and length are not per se considered.

Since 2002, geotechnical practitioners have compensated for structural anisotropy by various additions and edits to the GSI chart. Nevertheless, the fact remains that rock mass shear strength in directions parallel to defect set orientations may often be significantly less than in directions normal to such structural fabric.

The late Dr Barry McMahon $(1971,1974,1979)$ developed the original STEPSIM software for Monte-Carlo probabilistic simulation of Step-Paths (McMahon, personal communication, 1991; Read \& Lye 1983). The writer revised and upgraded STEPSIM to STEPSIM4 (Little et al. 1999). The two programs are coded in now dated computer languages FORTRAN'66 and FORTRAN'77, respectively. Strength models are developed on the basis of large numbers (say, 10,000+) Monte-Carlo simulations of failure-paths. Each path is, say, 500 to $1,000 \mathrm{~m}$ long. The simulation process is repeated for several normal stress conditions. A normal-shear stress relationship is developed. 
This paper describes an easier to use, Excel spreadsheet-based, Simplified Step-Path method (SSPM) approach. Variability in SSPM inputs is approximated by normal distributions. Rosenblueth $(1975,1981)$ logic of statistical moments, and Sampling Theory, are used to develop path-length dependent statistical strength models for specific directions through rock masses.

\section{Directional rock strength}

Anisotropy may exist at all scales of observation; from micro lamination in rock samples to overall layering in slopes.

Figure 1 shows the impact of sedimentary bedding/metamorphic layering on UCS of intact rock samples (Baczynski 2001). Directional strength reduction may exceed $60 \%$. This same strength anisotropy exists along circular failure paths through intact rock slopes; but is rarely considered by stability analysts.
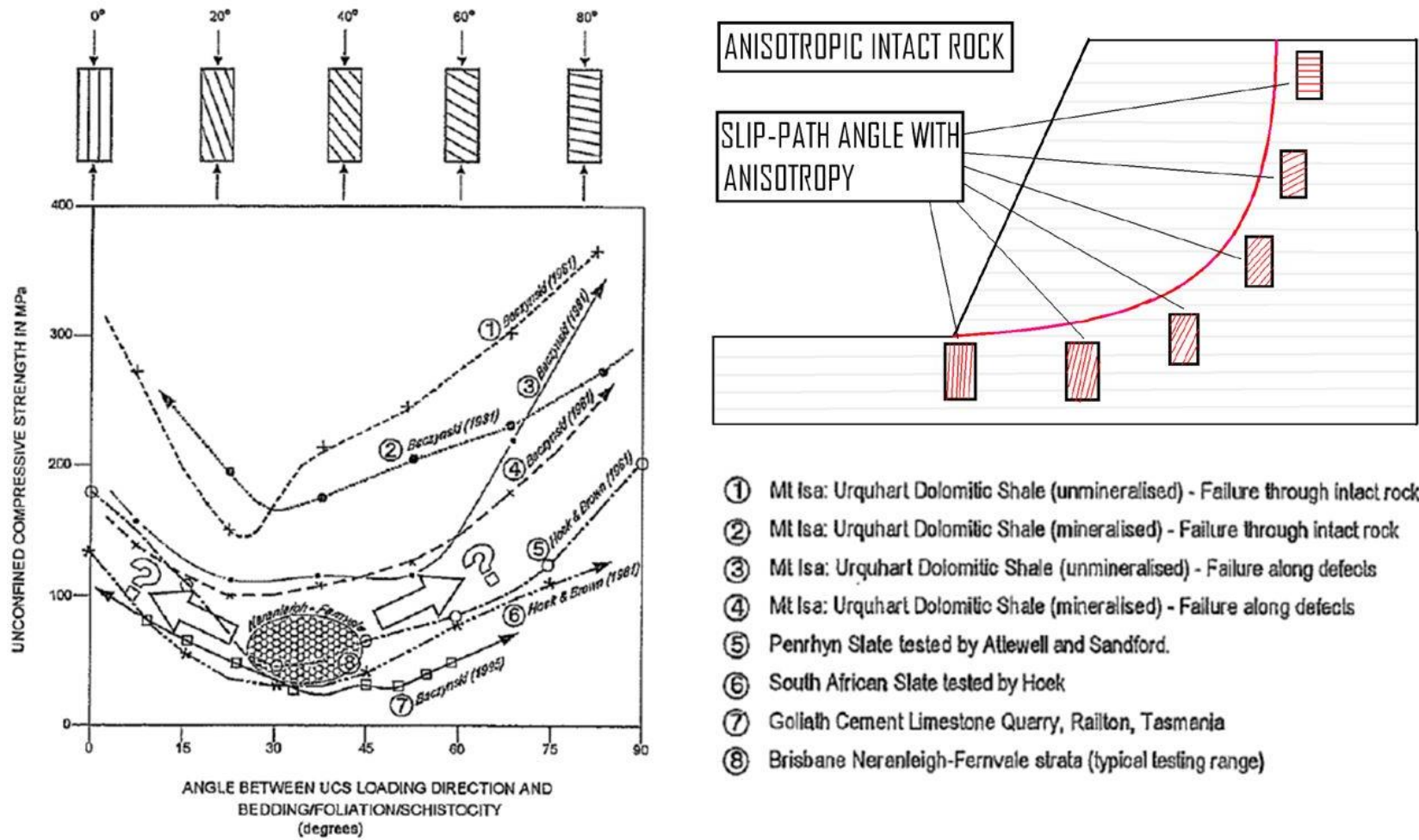

(1) Mt isa: Urquhert Dolomilic Shale (unmineralised) - Failure through inlact rock

(2) Mt Isa: Urquhart Dolomitic Shale (mineralised) - Failure through intact rock

(3) Mt Isa: Urquhart Dolomitic Shale (unmineralised) - Failure along defects

(4) Mt Isa: Urquhart Dolomitic Shale (mineralised) - Failure along defects

(5) Penrhyn Slate tested by Atlewell and Sandford.

(6) South Aitican Slate tested by Hock

(7) Goliath Cement Limestone Quarry, Railton, Tasmania

(8) Brisbane Neranleigh-Fernvale strata (typical testing range)

Figure 1 Layering anisotropy impact on UCS of intact rock test samples and along failure path through rock slope (Baczynski 2001)

Slopes comprising several different rock types (e.g. cyclic repetition of conglomerate, sandstone, siltstone, shale, mudstone, claystone and coal) exist at many mines, especially coal. Intact rock directional characteristics usually differ for each rock type. A weighted-average approach based on relative occurrence of each rock type is often used to estimate global properties for overall slopes.

Anisotropy is not just limited to strength, but also influences other rock properties (e.g. elasticity, mi parameter input to Hoek-Brown equations, and others).

\section{Directional Step-Path strength}

Apart from intact rock and stratigraphic considerations already mentioned, the Step-Path method specifically considers anisotropy imposed by patterns of geological defects.

There are four Step-Path outcomes.

- If there are no specific geological defect sets co-aligned with a particular direction through the rock mass, then the conventional Hoek-Brown strength model will apply in that direction (Figure 2(a)). 
- Where a geological defect set is co-aligned with a particular direction through the rock mass and a single member of the set is fully continuous through the rock slope, then this single defect will control shear strength in that direction (Figure 2(b)).

- Where a geological defect set is co-aligned with a particular direction through the rock mass but no single member of the set is fully continuous through the rock slope, then two or more defect members and respective intact rock or rock mass 'bridges' between those members will control shear strength in that direction (Figure 2(c)).

- Where two geological defect sets dip in the down slope direction and where at least the flatter set daylights in the slope face, then slope failure may involve shear sliding along the flatter set and progressive 'stepping-up' on the steeper set to create a step-like failure path. In this situation, for each defect set, two or more defect members and respective intact rock or rock mass 'bridges' between those members will control shear strength in the respective direction (Figure 2(d)).

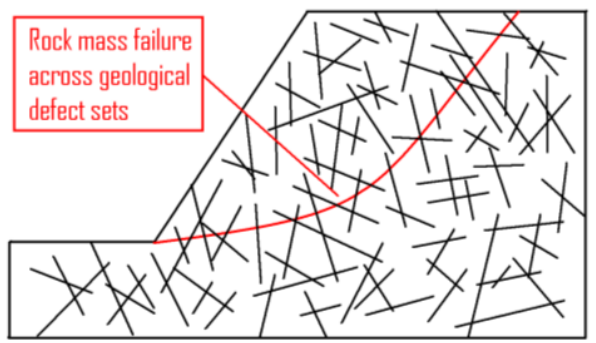

(a)

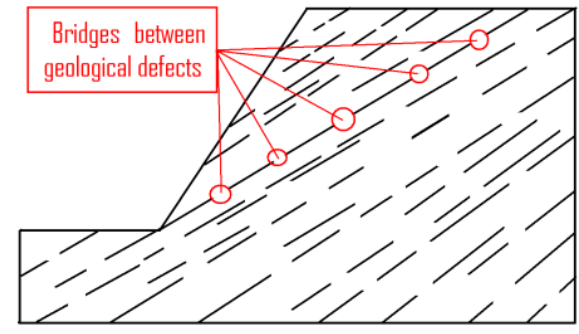

(c)

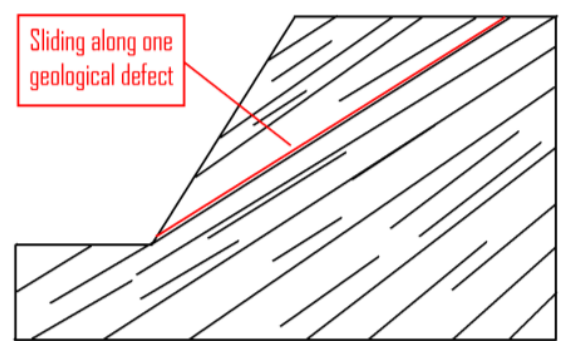

(b)

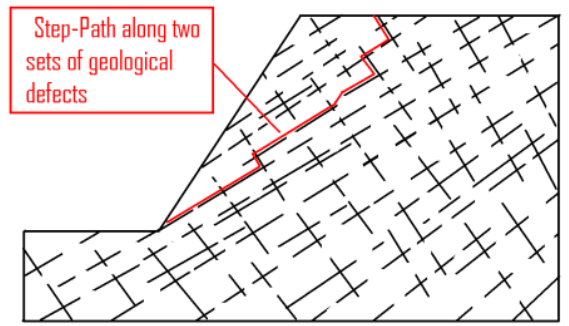

(d)

Figure 2 Appropriate shear strength models for various geological defect patterns in rock masses: (a) Hoek-Brown only rock mass strength applies; (b) one geological defect only strength applies; (c) one geological defect set and bridges Step-Path strength applies; and, (d) two geological defect sets and bridges Step-Path strength applies

If the cumulative length of the co-aligned defects is very much greater than the cumulative length of the bridges, then the directional shear strength through the rock mass will approach that of the defects. Conversely, if the cumulative length of the co-aligned defects is very much smaller than the cumulative length of the bridges, then the directional shear strength will approach the Hoek-Brown strength.

The words 'very much greater' and 'very much smaller' are purposely stated vaguely, as the relative contribution of geological defects and bridges to the overall shear strength will entirely depend on the actual strength characteristics of each of these two components.

\section{$4 \quad$ Slope failure modes}

The first mandatory step in all rock mass slope assessments is a kinematic stability analysis. This task is required to identify slope failure modes and specific geological defect sets associated with each mode.

If the Hoek-Brown method is automatically used to develop the rock mass strength, and the slope stability is always assessed by a circular slip algorithm, then inexperienced analysts may fail to consider other perhaps more critical failure modes that may yield less optimistic stability answers for some slopes. 
The Step-Path directional shear strength estimate approach can be applied to all failure modes; along either the full or partial length of the failure path through the rock mass slope. This includes circular or quasi circular (Figure 3(a)), planar (Figure 2(c)), Step-Path (Figure 2(d)), tetrahedral wedge (Figure 3(b)), active-passive wedge (Figure 3(c)) and toppling (Figure 3(d)).

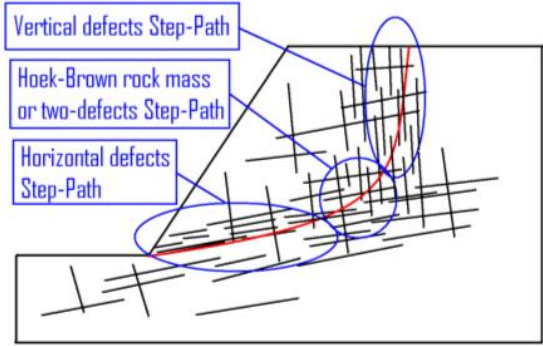

(a)

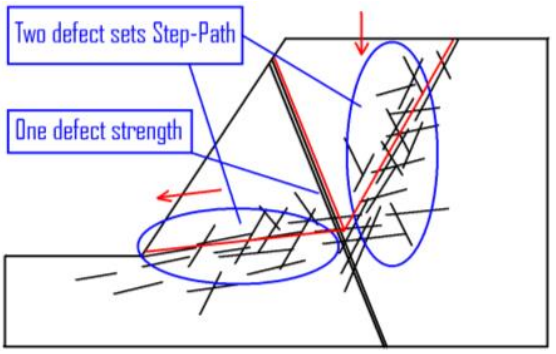

(c)

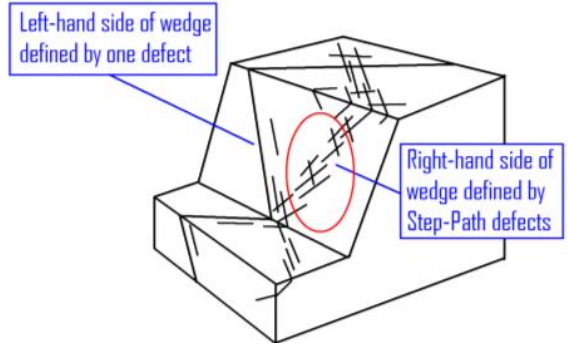

(b)

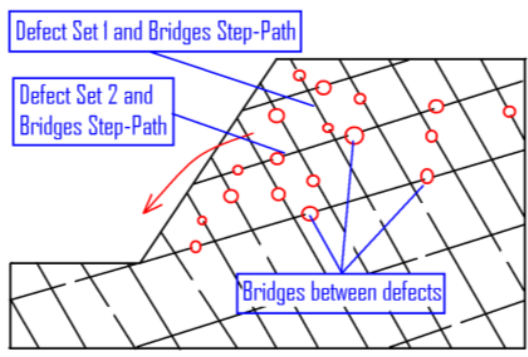

(d)

Figure 3 Additional examples of Step-Path method use for various failure modes of rock mass slopes:

(a) circular and quasi-circular slip; (b) tetrahedral wedge slip; (c) active-passive wedge slip; and, (d) slope toppling

\section{$5 \quad$ Step-Path inputs}

A Step-Path rock mass slope is visualised as comprising a network of equal-sized blocks or cells (Figure 4(a)). Other Step-Path concepts are shown in Figures 4(b) to 4(d).

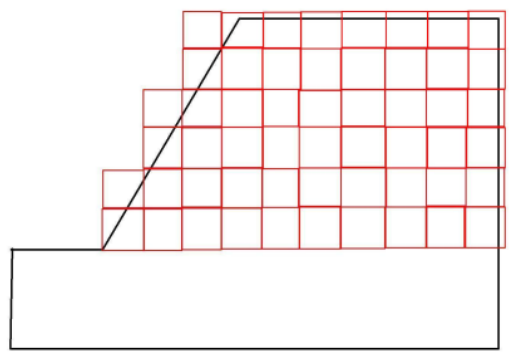

(a)

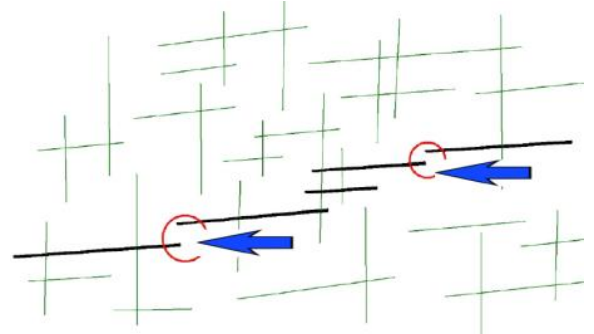

(c)
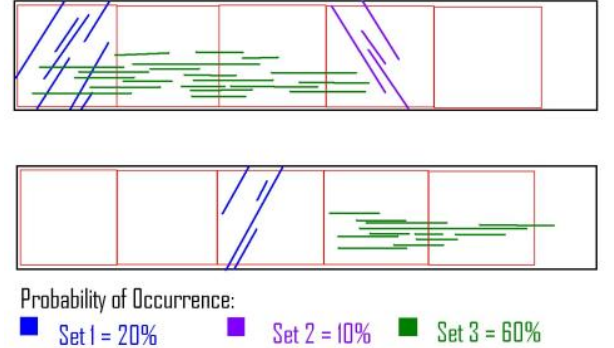

(b)

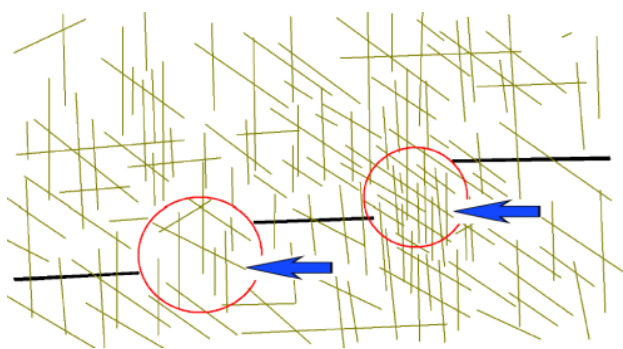

(d)

Figure 4 Some Step-Path concepts: (a) slope visual as a network of cells/blocks; (b) probability of occurrence for defect sets; (c) intact rock 'bridges' between flat defects; and, (d) rock mass 'bridges' between flat defects 
Step-Path strength determinations require the following statistical models for each geological defect set that is relevant to the analysis.

- Defect dip angle (i.e. statistical model type - normal, lognormal; mean, -1 and +1 standard deviation).

- Probability of defect occurrence in each STEPSIM4 rock mass block (0-100\%).

- Defect length (i.e. statistical model type - normal, lognormal; mean, -1 and +1 standard deviation).

- Defect shear strength (i.e. effective friction and cohesion for the designated normal stress).

- Defect cut-off (i.e. probability that defects are truncated by other defects; 0-100\%).

- Length of intact rock/rock mass bridges between non cut-off defects (i.e. statistical model type normal, lognormal; mean, -1 and +1 standard deviation).

- Intact rock/rock mass bridge strength (i.e. effective friction and cohesion for the designated normal stress).

\section{Original STEPSIM and revised STEPSIM4}

Akin to Figure 4(a), the slope is broadly visualised as comprising a network of equal-size blocks. Where, say, two sets of geological defects occur along a Step-Path traverse through a rock mass slope, a statistically based Monte-Carlo simulation approach is used to sequentially generate this traverse (comprising defects, bridges and rock mass elements). The simulation process starts at the toe of the slope and continues up to a backscarp location on the ground behind the crest of the slope (Figures 2(d) and 5).

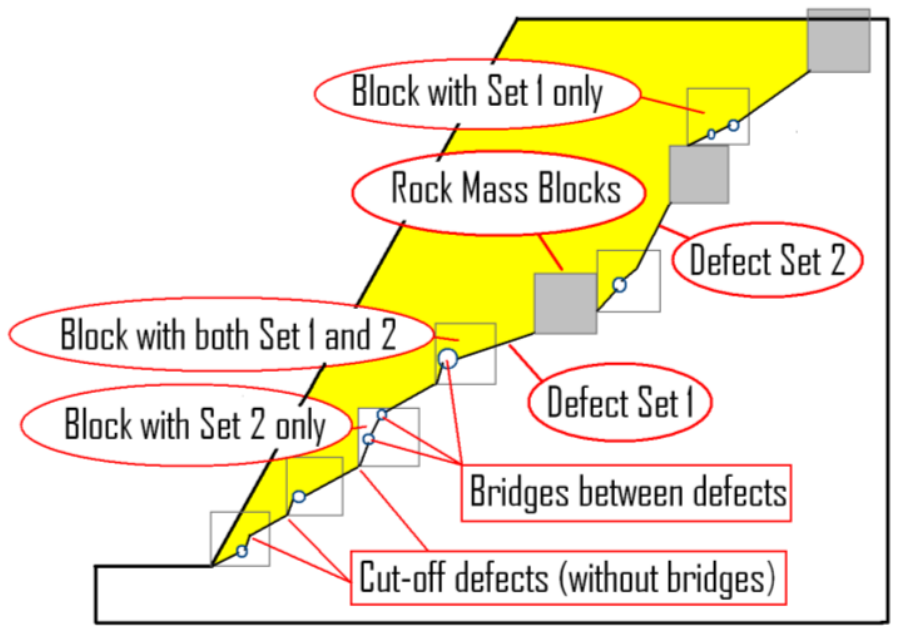

Figure 5 Example of revised STEPSIM4 Monte-Carlo simulated Step-Path through rock slope

The revised STEPSIM4 software (Little et al. 1999; Baczynski 2000) had several enhancements. For example, cyclicity of the random number generator was increased from $<600$ to $\pm 80,000$, normal and lognormal statistical models were made available for input parameters, both weak (say, clay-breccia filled faults) and strong (say, sulphides filled joints) members could be simulated for specific defect sets, both intact rock and rock mass 'bridges' could be modelled between defects, the maximum allowable number of statistically generated Step-Path traverses through the simulated slope was increased from just 400 to 15,000; and so on. However, the most significant upgrade was perhaps the ability of STEPSIM4 to honour the Monte-Carlo generated lengths for the defects. The original STEPSIM software simply truncated defect length at the up-slope boundary of square blocks into which the slope was partitioned. STEPSIM4 honours all Monte-Carlo generated defect lengths. If needed, STEPSIM4 allows defects to continue beyond block boundaries. If this continuation occurs, then the next block no longer abuts the previous block, but starts at 
the up-slope end of the defect continued beyond the previous block edge (Figure 5). Thereby, maximum lengths were no longer limited by block dimensions (e.g. $<7.1 \mathrm{~m}$ for $5 \mathrm{~m}$ by $5 \mathrm{~m}$ blocks or $<14.1 \mathrm{~m}$ for $10 \mathrm{~m}$ by $10 \mathrm{~m}$ blocks). With this constraint removed, actual fault lengths (say, $100 \mathrm{~m}$ ) can now be included along Step-Path traverses through rock slopes.

\section{$7 \quad$ Simplified Step-Path method}

The Simplified Step-Path Method (SSPM) still requires statistical models for the same suite of inputs as were used for STEPSIM and STEPSIM4 Monte-Carlo simulations. Figure 6 shows the general SSPM strength equation.

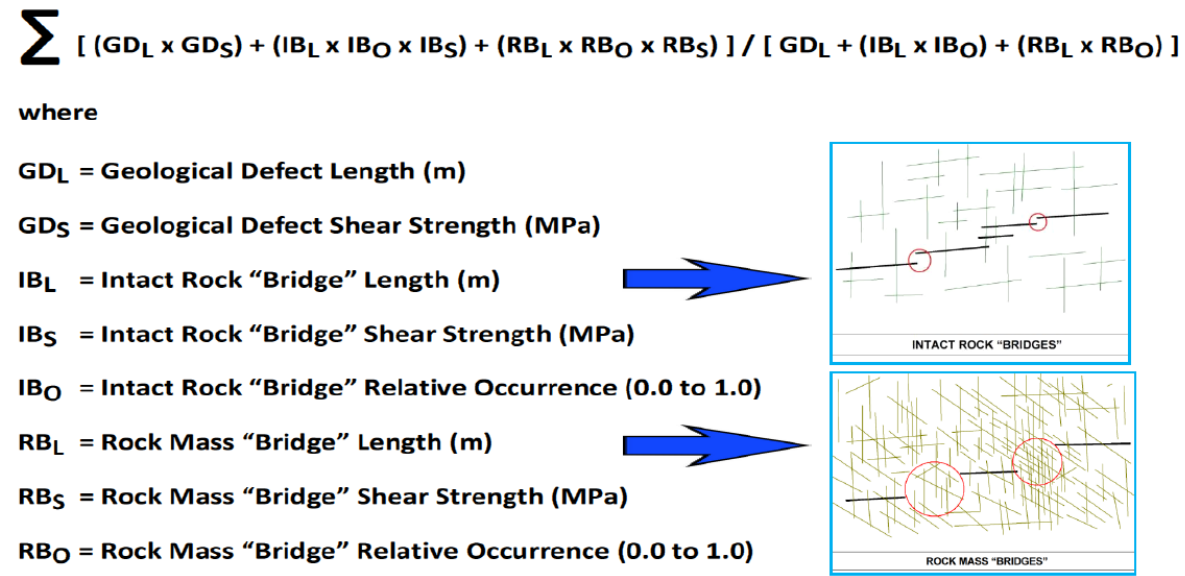

Figure 6 SSPM: general form of strength equation

The SSPM strength equation is a numerator divided by a denominator.

The numerator is the combined sum of the (mean defect length multiplied by its mean strength), plus the (mean intact rock bridge length multiplied by its mean strength multiplied by its relative occurrence ratio), plus the (mean rock mass bridge length multiplied its mean strength multiplied by its relative occurrence ratio).

The denominator is the combined sum of (mean defect length), plus the (mean intact rock length multiplied by its relative occurrence ratio), plus the (mean rock mass bridge length multiplied by its relative occurrence ratio).

The relative occurrence ratio ranges between 0 and 1 .

Differences in the SSPM inputs and Step-Path analyses are:

- Statistical models for all parameters are approximated as normally-distributed (i.e. no lognormal models).

- Barton (1976) joint strength model is used for all non-fault defects.

- Rosenblueth $(1975,1981)$ method of statistical moments (i.e. which considers all possible combinations of -1 and +1 standard deviation values for the input parameters) is used to develop the statistical Step-Path strength model.

- For a user nominated suite of normal stresses the resulting Step-Path strengths are output as both the shear stress and the equivalent effective friction and effective cohesion values.

- Step-Path strength model is normally distributed; the mean and \pm 1 standard deviation values are output.

- All analyses are achieved via Excel spreadsheets. 
SSPM computed Step-Path shear strength models provide input to conventional limit equilibrium and numerical modelling rock slope stability analyses.

\section{Rosenblueth method}

The Rosenblueth $(1975,1981)$ method of statistical moments is based on two principles:

- If values for each of the parameter inputs to an analysis are normally-distributed, then the analysis output values will likewise be normally distributed.

- For the above statistical conditions, the normally-distributed analysis output model can be derived just by undertaking the analysis for every combination of the -1 and +1 standard deviation values of the input parameters.

On the basis of the second principle, the total number of analyses that must be completed is related to the number of input parameters being considered. The number of analyses is determined by raising 2 to the power $\mathrm{N}$, where $\mathrm{N}$ is the number of input parameters.

Thus, where the model comprises 2, 3, 4, 5, 6, 7 and 8 input parameters, the number of required analyses will be $4,8,16,32,64,128$ and 256 , respectively.

The Rosenblueth approach has now been routinely applied (i.e. last $40+$ years) to stability analysis of soil slopes. For a simple slope comprising only one material, there may be four input parameters - friction angle, cohesion, density and groundwater pressures. If each of these parameters is statistically distributed, then 16 slope stability analyses considering the \pm 1 standard deviation input values are required to develop a statistical model for the distribution of Factors of Safety. If density and groundwater are assumed constant inputs, then there will be just two statistically variable inputs and only 4 slope stability analyses will be required to ascertain the distribution of Factors of Safety. To further reduce analysis effort, the material strength model for each slope layer could also be expressed as a shear strength input, rather than being specified by two inputs (friction angle and associated cohesion).

Generally speaking, as the number of considered inputs exceeds 5 to 6 , the required stability effort becomes quite considerable. This is an underlying reason for development of Monte-Carlo based simulation approaches such as STEPSIM and STEPSIM4 as these are able to process quite complex geotechnical models with large numbers of statistically-distributed input parameters.

Table 1 is an example of Rosenblueth application to Hoek-Brown strength estimation, where GSI and D are kept constant. Table 2 shows Rosenblueth application to stability analysis of a slope comprising five layers.

Table 1 Example of Rosenblueth method applied to Hoek-Brown rock mass strength estimate

\begin{tabular}{ccccccccc}
\hline \multicolumn{2}{c}{ UCS (MPa) } & \multicolumn{2}{c}{ mi } & \multicolumn{5}{c}{ Normal stress (MPa) } \\
\hline St Dev & Strength & St Dev & mi & $\mathbf{0 . 0 0}$ & $\mathbf{2 . 0 0}$ & $\mathbf{5 . 0 0}$ & $\mathbf{1 0 . 0 0}$ & $\mathbf{1 5 . 0 0}$ \\
\cline { 5 - 9 } & & & & \multicolumn{5}{c}{ Shear (MPa) } \\
\hline+1 & 153 & +1 & 6.95 & 33.21 & 35.34 & 38.42 & 43.31 & 47.95 \\
+1 & 153 & -1 & 5.35 & 37.00 & 38.81 & 41.43 & 45.62 & 49.63 \\
\hline-1 & 73 & +1 & 6.95 & 15.84 & 17.94 & 20.89 & 24.40 & 29.55 \\
\hline-1 & 73 & -1 & 5.35 & 17.64 & 19.43 & 21.96 & 25.87 & 29.50 \\
& & & Mean & 25.92 & 27.88 & 30.68 & 34.80 & 39.16 \\
\hline & & & St Dev & 10.74 & 10.73 & 10.76 & 11.22 & 11.14 \\
\hline
\end{tabular}

The Rosenblueth approach can be applied to most geotechnical applications that consider several inputs. Obvious examples include Barton Q-index and joint shear strength, Bieniawski RMR, Laubscher MRMR, as well as Hoek-Brown GSI and their rock mass shear strength (Baczynski et al. 2001). 
Table 2 Example of Rosenblueth method applied to computing Factor of Safety (FS) for slope comprising five different strength domains/layers

\begin{tabular}{|c|c|c|c|c|c|c|c|}
\hline \multirow[t]{2}{*}{$\begin{array}{l}\text { Slope stability } \\
\text { analysis run number }\end{array}$} & \multicolumn{5}{|c|}{$\begin{array}{l}\text { Rosenblueth method of probability moments } \\
\text { (all combinations of }+/-1 \text { standard deviations) }\end{array}$} & \multirow[t]{2}{*}{$\begin{array}{l}\text { Computed FS } \\
\text { (constant mi) }\end{array}$} & \multirow[t]{2}{*}{$\begin{array}{l}\text { Computed FS } \\
\text { (variable mi) }\end{array}$} \\
\hline & Layer 5 & Layer 4 & Layer 3 & Layer 2 & Layer 1 & & \\
\hline 1 & + & + & + & + & + & 3.70 & 4.87 \\
\hline 2 & - & + & + & + & + & 3.39 & 4.52 \\
\hline 3 & + & - & + & + & + & 2.77 & 3.56 \\
\hline 4 & + & + & - & + & + & 3.14 & 4.09 \\
\hline 5 & + & + & + & - & + & 3.25 & 4.28 \\
\hline 6 & + & + & + & + & - & 3.23 & 4.22 \\
\hline 7 & - & - & + & + & + & 2.50 & 3.25 \\
\hline 8 & - & + & - & + & + & 2.83 & 3.77 \\
\hline 9 & - & + & + & - & + & 2.96 & 3.94 \\
\hline 10 & - & + & + & + & - & 3.05 & 4.02 \\
\hline 11 & + & - & - & + & + & 2.34 & 2.72 \\
\hline 12 & + & + & - & - & + & 2.90 & 3.47 \\
\hline 13 & + & + & + & - & - & 3.21 & 4.00 \\
\hline 14 & + & - & + & - & + & 2.62 & 2.96 \\
\hline 15 & + & + & - & + & - & 3.03 & 3.60 \\
\hline 16 & + & - & + & + & - & 2.68 & 3.13 \\
\hline 17 & - & - & - & + & + & 1.96 & 2.436 \\
\hline 18 & + & - & - & - & + & 2.06 & 2.16 \\
\hline 19 & + & + & - & - & - & 2.79 & 3.35 \\
\hline 20 & - & + & - & - & + & 2.56 & 3.16 \\
\hline 21 & + & - & + & - & - & 2.45 & 2.89 \\
\hline 22 & - & + & - & + & - & 2.70 & 3.40 \\
\hline 23 & - & - & + & - & + & 2.28 & 2.69 \\
\hline 24 & - & - & + & + & - & 2.37 & 2.96 \\
\hline 25 & - & + & + & - & - & 2.94 & 3.79 \\
\hline 26 & + & - & - & + & - & 2.10 & 2.44 \\
\hline 27 & + & - & - & - & - & 1.86 & 2.12 \\
\hline 28 & - & + & - & - & - & 2.47 & 3.16 \\
\hline 29 & - & - & + & - & - & 2.15 & 2.69 \\
\hline 30 & - & - & - & + & - & 1.85 & 2.24 \\
\hline 31 & - & - & - & - & + & 1.71 & 1.93 \\
\hline \multirow[t]{3}{*}{32} & - & - & - & - & - & 1.64 & 1.93 \\
\hline & & & & Mean FS & & 2.61 & 3.24 \\
\hline & & & & t. Dev. FS & & 0.52 & 0.78 \\
\hline
\end{tabular}

\section{$9 \quad$ Sampling Theory and standard deviation}

The \pm 1 standard deviation range for Step-Path strength is directly related to the slope block-sizes (see Figures 4(a), 4(b) and 5) that the geotechnical analyst had adopted for collecting and processing of the field and laboratory data. For example, probability of occurrence for a specific defect set is directly related to block-size; the larger the block the greater the probability. Block-sizes of $5 \times 5 \mathrm{~m}, 10 \times 10 \mathrm{~m}$ or $15 \times 15 \mathrm{~m}$ are often used. 
Where the rock slope comprises just one domain of geotechnical conditions, length of the failure path through the slope depends on the failure path shape and slope height. Where the rock slope comprises several domains, only segments of the overall failure path will traverse though any specific domain. However, in most instances, failure path segments are much longer than block-size dimensions.

Once the length of failure path segments in each geotechnical domain is estimated, the mean Step-Path strength for a specific geotechnical domain remains unchanged, but Sampling Theory needs to be used to adjust SSPM computed \pm 1 standard deviation for Step-Path strength range (as, say, might have been estimated for 5 by $5 \mathrm{~m}$ blocks) to one that is statistically appropriate for the length of the respective failure path segment in that specific domain.

Figure 7 illustrates concepts of geotechnical domains, 'Sampling Theory' and strength standard deviation adjustment procedure. Figure 8 shows Sampling Theory applied to UCS of intact rock samples. As the number of test samples in a batch increases, the standard deviation for the mean determined for each batch decreases. The shown mismatch between actual and predicted outcomes is due to the simplistic and exclusive way that the writer had selected the UCS samples included in each batch; but the result is still sufficient to demonstrate the general trend.

SLIP-PATH LENGTH = I6 $\times$ WINDOW SIZE

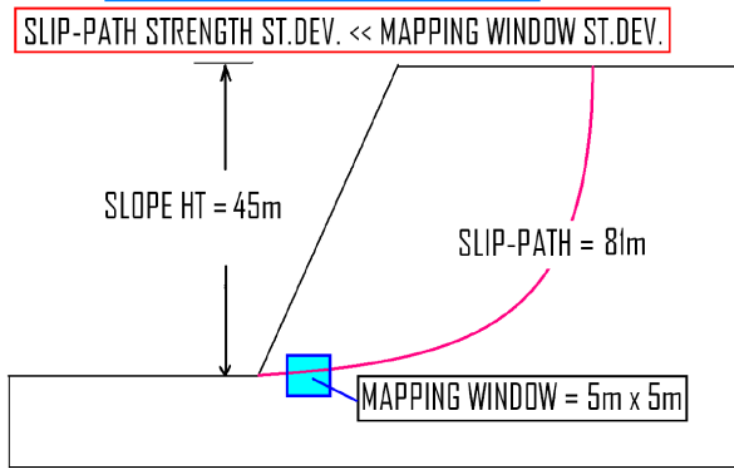

(a)

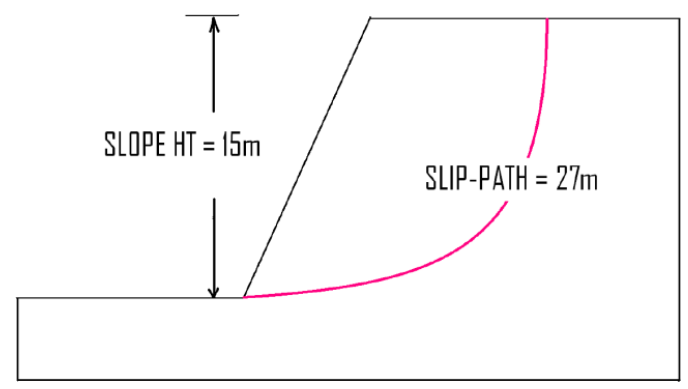

(b)

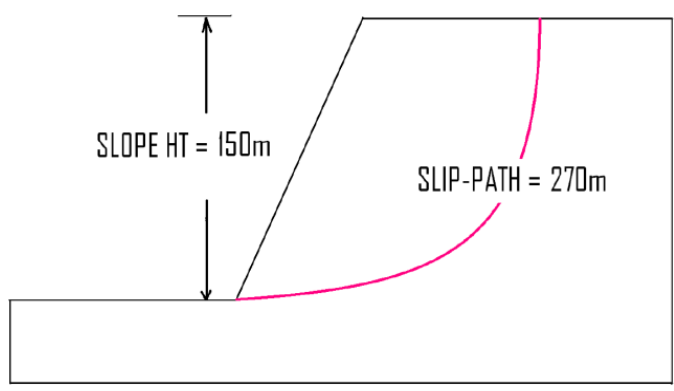

(c)

(d)

$$
\begin{aligned}
& \mathrm{SD}_{T}=\left[\left(\mathrm{SD}_{K} \times \mathrm{SD}_{K}\right) /\left(\mathrm{L}_{T} / \mathrm{L}_{K}\right)\right]^{0.5} \\
& \mathrm{SD}_{K}=\text { Standard Deviation for "Known" Path-length } \\
& \mathrm{SD}_{T}=\text { Standard Deviation for "Target" Path-length } \\
& \mathrm{L}_{K}=\text { "Known" Path-Length } \\
& \mathrm{L}_{T}=\text { "Target" Path-Length }
\end{aligned}
$$

"Known" Length \& GSI SD: 5m \& 25

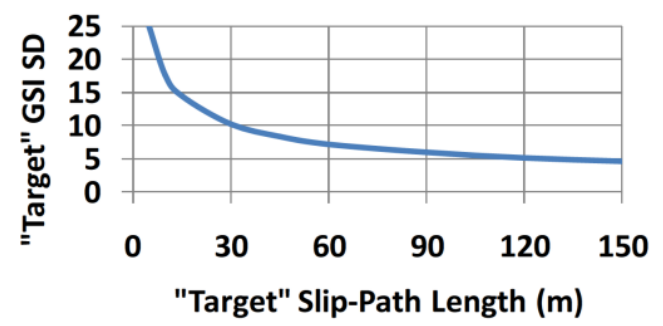

(e)

Figure 7 Sampling Theory and standard deviation adjustment procedure for Step-Path strength:

(a) example of scale relationship between mapping window/block-size, slope height and Slip-Path length; (b) $15 \mathrm{~m}$ high slope; (c) $150 \mathrm{~m}$ high slope; (d) Sampling Theory equation for adjusting standard deviation; and, (e) conceptual example of Sampling Theory adjustment (where, mapping window $=5 \times 5 \mathrm{~m}$; GSI St. Dev. $=25$ for mapped window dimensions) 


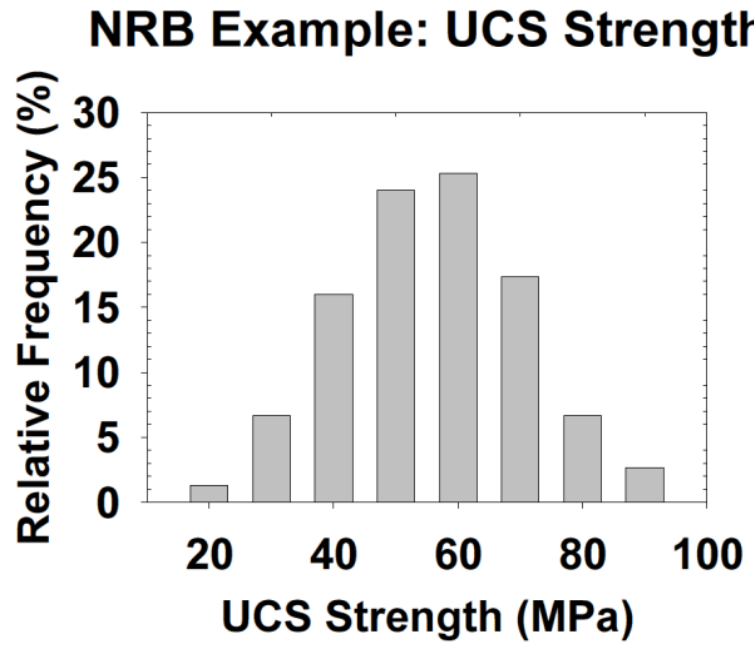

(a)

\begin{tabular}{|c|c|c|c|c|}
\hline \multicolumn{5}{|c|}{ UCS Strength Tests (MPa) } \\
\hline \multirow{2}{*}{$\begin{array}{c}\text { No. Tests } \\
\text { in Batch }\end{array}$} & \multicolumn{2}{|c|}{ Actual } & \multicolumn{2}{c|}{ Predicted } \\
\cline { 2 - 5 } & Mean & St. Dev. & Mean & St. Dev. \\
\hline 1 & 51.43 & 15.72 & 51.43 & 15.72 \\
\hline 3 & 52.94 & 10.99 & 51.43 & 9.08 \\
\hline 5 & 52.42 & 8.42 & 51.43 & 7.03 \\
\hline 10 & 51.69 & 5.13 & 51.43 & 4.97 \\
\hline 15 & 50.94 & 4.48 & 51.43 & 4.06 \\
\hline 20 & 51.35 & 3.52 & 51.43 & 3.52 \\
\hline 25 & 51.41 & 3.45 & 51.43 & 3.14 \\
\hline
\end{tabular}

(c)
NRB Example: UCS Strength

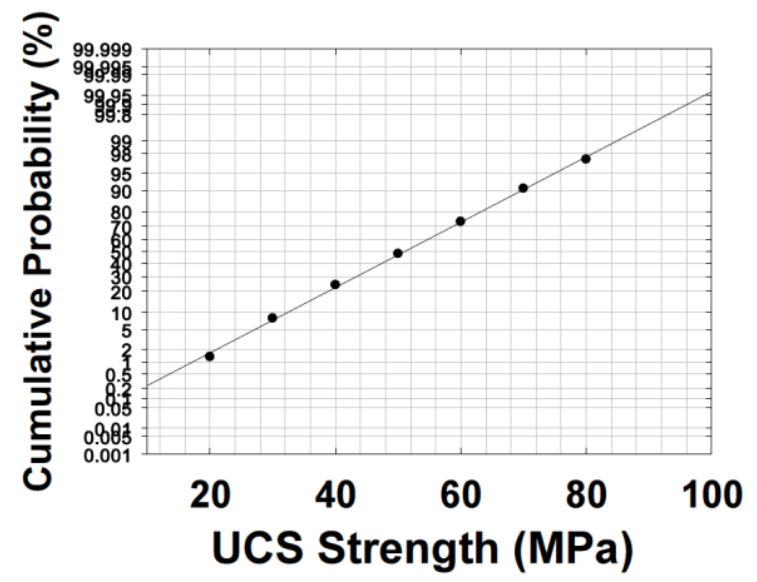

(b)

Example: UCS Strength (MPa) Tests

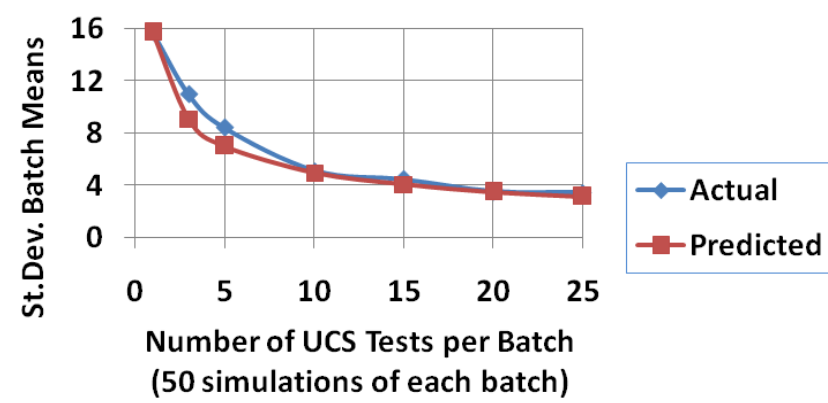

(d)

Figure 8 Example of Sampling Theory adjustment of UCS standard deviation for number of test samples comprising a randomly selected batch/group: (a) UCS: relative frequency distribution;

(b) UCS: cumulative frequency distribution; (c) table of computed and predicted St. Dev. Values; and, (d) graph of computed and predicted St. Dev. values

\section{Case study inputs to Simplified Step-Path method}

The SSPM was used on an Asian multi-seam coal mining project during 2010. Existing open pit workings were spread over a lease area of about $30 \times 30 \mathrm{~km}$. Pit depths were typically $50 \times 200 \mathrm{~m}$. Some of the areas had been mined underground in the past. Significantly larger and much deeper pits were being contemplated in areas outside, but in near proximity of the existing mine lease.

Figures 9 to 11 and Tables 3 to 5 document the following:

- Conceptual slope model adopted for the rock slope.

- Geotechnical field data collected by the writer in several existing open pit areas across the lease.

- Laboratory test data provided by the mine owners.

- Examples of statistical Step-Path shear strength models developed for input to stability analyses. 


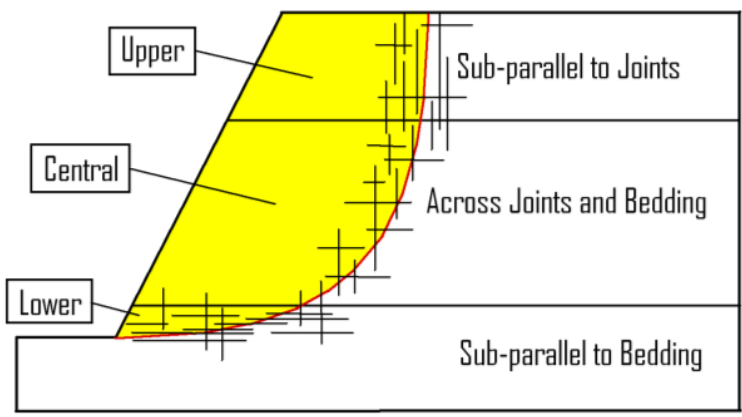

(a)

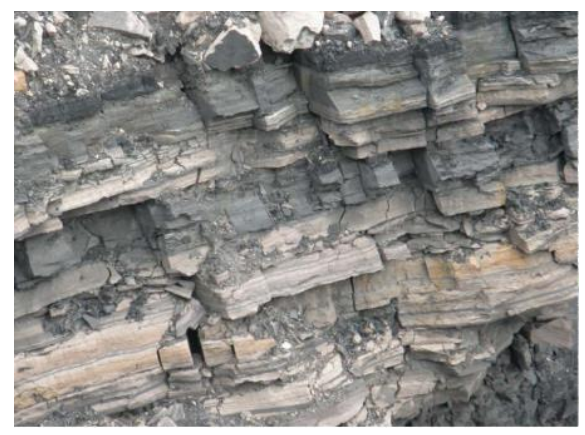

(c)

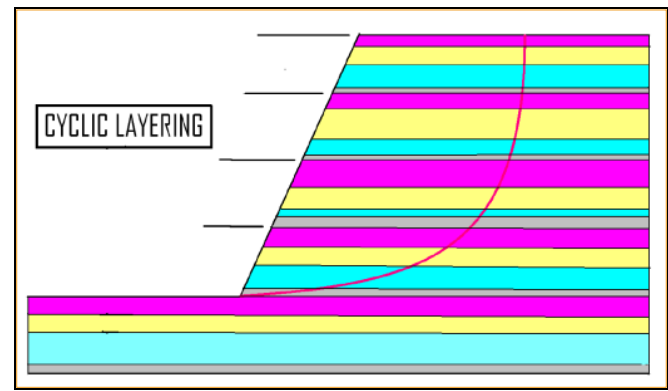

(e)

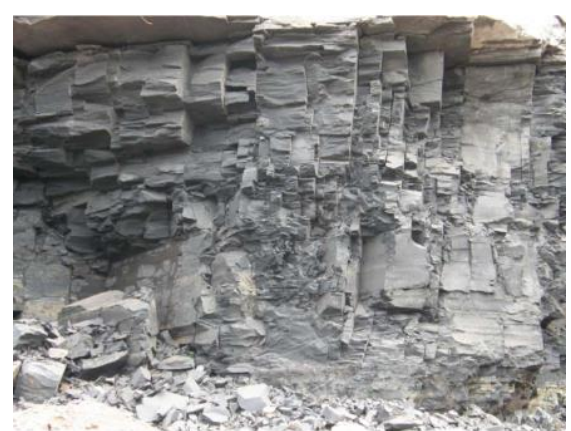

(b)

- Bedding plane partings: 115 / 02 ( \pm 4 / \pm 4$)$ (Major)

- Joint Set J1: $220 / 85( \pm 11 / \pm 5)$ (Major)

- Joint Set J2: $260 / 75$ ( $\pm 6 / \pm 5)$ (Intermediate)

- Joint Set J3: 315 / 80 ( \pm 10 / \pm 5 ) (Minor to perhaps intermediate)

- Joint Set J4 / Shear Set S1: 230 / 50 ( \pm 4 / \pm 4 ) (Minor)

- Joint Set J5 / Shear Set S2: $305 / 50$ ( \pm 4 / I4) (Minor)

- Joint Set J6 / Shear Set S3: 005 / 60 ( \pm 4 / \pm 4 ) (Minor)

(d)

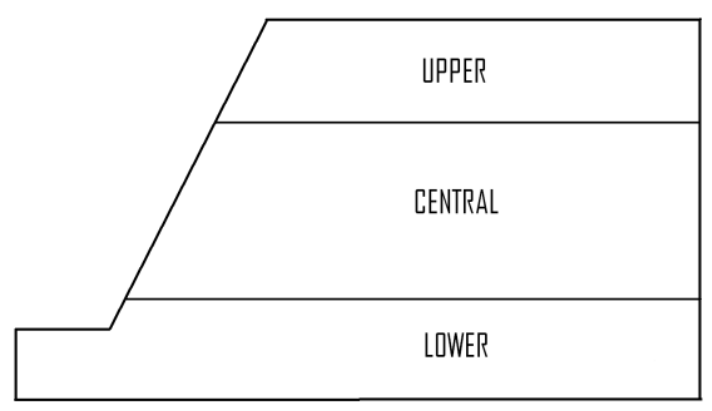

(f)

Figure 9 Case study: slope partitioned into Slip-Path trend domains relative defect set orientations and statistical model for defect set orientations and relative occurrence: (a) slope partitioned into defect-controlled Slip-Path domains; (b) upper Slip-Path domain controlled by sliding on near-vertical defects and bridges between them; (c) lower Slip-Path domain controlled by sliding on near-horizontal bedding planes and rock bridges between them; and, (d) orientation model for geological defects (e) example of cyclic layering (f) upper, central and lower Step-Path domains 


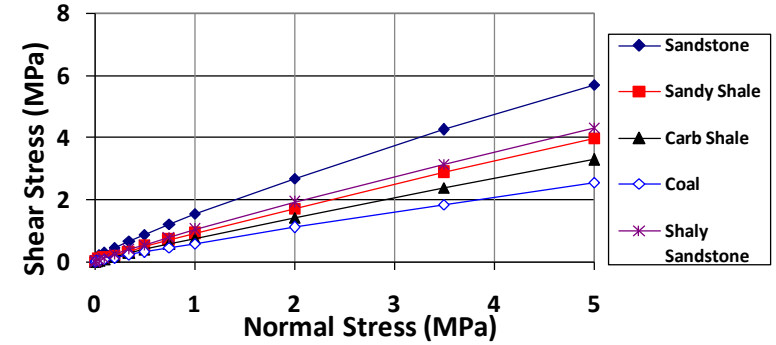

(a)

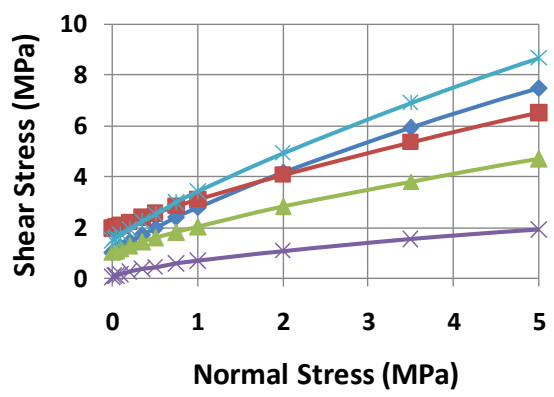

(c)

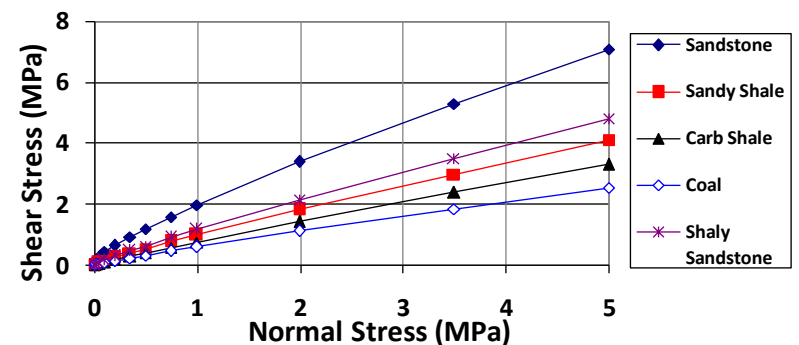

(b)

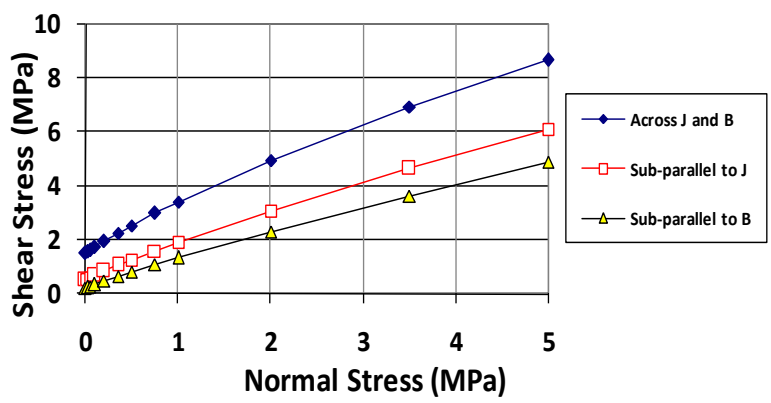

(d)

Figure 10 Case study: examples of Hoek-Brown and SSPM strength models for slope: (a) bedding planes shear strength model for each rock type; (b) joints - shear strength model for each rock type; (c) mean Hoek-Brown rock mass strength models for each rock type; and, (d) mean Step-Path strength for shaly sandstone in each Slip-Path domain (i.e. upper, central and lower domains)

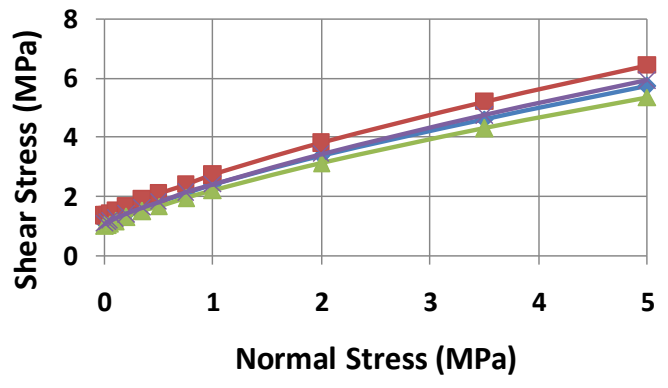

(a)

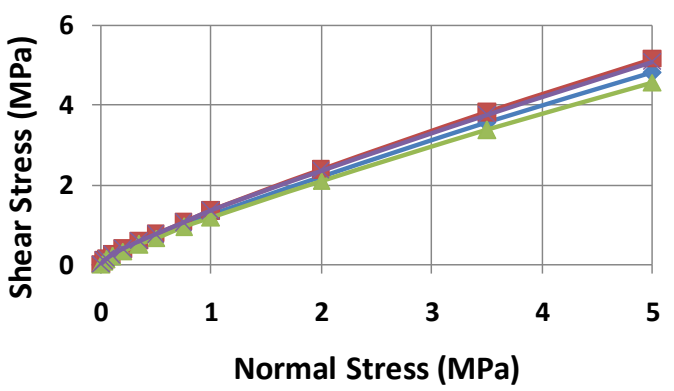

(c)

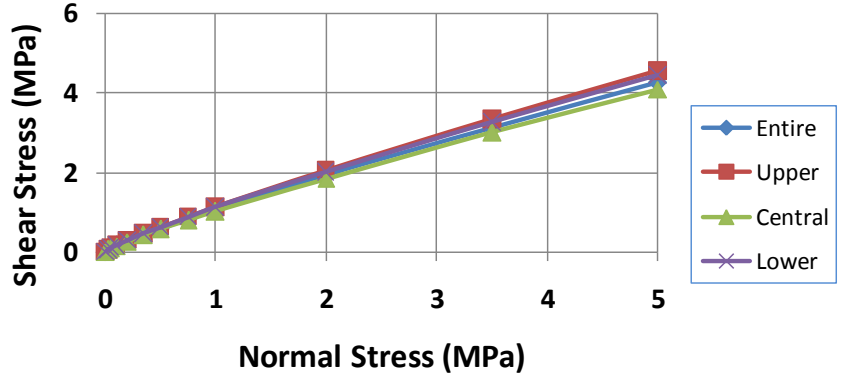

(b)

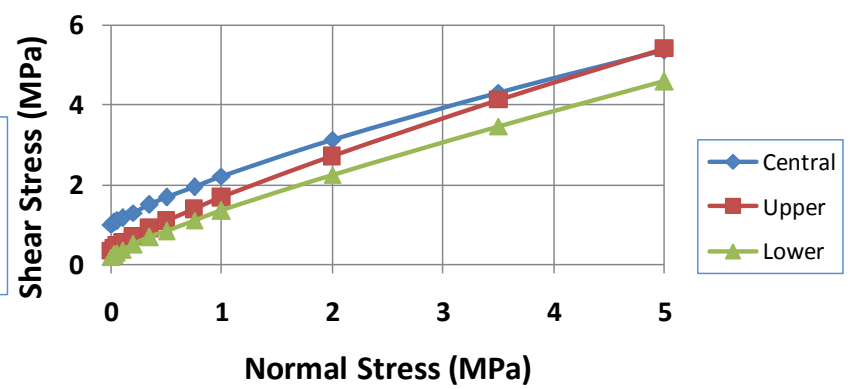

(d)

Figure 11 Case study: Examples of weighted-average (by the relative proportion of each rock type in the strata) Hoek-Brown and SSPM strength models for various Slip-Path domains (entire slope, upper, central and lower) in the slope: (a) mean Hoek-Brown rock mass shear strength;

(b) mean bedding plane shear strength; (c) mean vertical joint shear strength; and, (d) mean failure-path strength (i.e. upper: joints Step-Path, central: Hoek-Brown only and lower: bedding planes Step-Path) 
Table 3 Case study: slope design model for geological defects

\begin{tabular}{|c|c|c|c|c|c|c|c|c|c|c|}
\hline \multirow{3}{*}{ Rock type } & \multicolumn{9}{|c|}{ Main joint set } & \multirow{3}{*}{$\begin{array}{c}\text { Defect } \\
\text { cut-off } \\
(\%)\end{array}$} \\
\hline & \multicolumn{3}{|c|}{ Length ( $m$ ) } & \multicolumn{3}{|c|}{ Spacing $(\mathrm{m})$} & \multicolumn{3}{|c|}{$\mathrm{RM}^{*}$ bridge length (m) } & \\
\hline & Statistics+ & Min & Max & Statistics+ & Min & Max & Statistics+ & Min & Max & \\
\hline Sandstone & $3.0 \pm 2.5$ & 0.2 & 10.0 & $3.0 \pm 2.0$ & 0.1 & 20.0 & $1.5 \pm 1.0$ & 0.1 & 5.0 & 10.0 \\
\hline Sandy shale & $2.0 \pm 1.5$ & 0.3 & 10.0 & $1.0 \pm 0.5$ & 0.1 & 10.0 & $0.5 \pm 0.3$ & 0.1 & 2.0 & 20.0 \\
\hline Carb. shale^ & $2.0 \pm 1.5$ & 0.3 & 10.0 & $1.5 \pm 1.0$ & 0.1 & 10.0 & $0.7 \pm 0.3$ & 0.1 & 2.0 & 40.0 \\
\hline Coal & $0.7 \pm 0.5$ & 0.05 & 5.0 & $1.0 \pm 0.05$ & 0.01 & 1.0 & $0.03 \pm 0.02$ & 0.01 & 0.1 & 80.0 \\
\hline \multicolumn{11}{|c|}{ Second joint set } \\
\hline Sandstone & $2.0 \pm 1.5$ & 0.1 & 5.0 & $4.0 \pm 3.0$ & 0.1 & 30.0 & $2.5 \pm 1.5$ & 0.5 & 5.0 & 5.0 \\
\hline Sandy shale & $1.5 \pm 1.0$ & 0.5 & 5.0 & $2.0 \pm 1.5$ & 0.3 & 15.0 & $0.5 \pm 0.3$ & 0.2 & 5.0 & 10.0 \\
\hline Carb. shale ${ }^{\wedge}$ & $2.0 \pm 1.5$ & 0.4 & 5.0 & $2.5 \pm 2.0$ & 0.1 & 10.0 & $0.7 \pm 0.4$ & 0.1 & 2.0 & 30.0 \\
\hline Coal & $0.5 \pm 0.4$ & 0.05 & 5.0 & $0.1 \pm 0.05$ & 0.01 & 1.0 & $0.03 \pm 0.02$ & 0.01 & 0.05 & 80.0 \\
\hline \multicolumn{11}{|c|}{ Bedding planes } \\
\hline Sandstone & $5.0 \pm 4.0$ & 1.0 & 50.0 & $1.0 \pm 0.5$ & 0.3 & 3.0 & $1.5 \pm 1.0$ & 0.2 & 5.0 & 20.0 \\
\hline Sandy shale & $4.0 \pm 3.0$ & 0.1 & 20.0 & $0.6 \pm 0.4$ & 0.1 & 2.0 & $0.5 \pm 0.3$ & 0.1 & 3.0 & 40.0 \\
\hline Carb. shale ${ }^{\wedge}$ & $5.0 \pm 4.0$ & 0.5 & 20.0 & $0.4 \pm 0.3$ & 0.05 & 1.0 & $1.0 \pm 0.5$ & 0.05 & 3.0 & 70.0 \\
\hline Coal & $5.0 \pm 4.0$ & 0.05 & 50.0 & $0.1 \pm 0.05$ & 0.01 & 0.5 & $0.15 \pm 0.1$ & 0.01 & 2.0 & 80.0 \\
\hline \multicolumn{11}{|c|}{ Defect surface roughness and base friction angle (degrees) } \\
\hline \multicolumn{11}{|c|}{ All joint sets } \\
\hline & \multicolumn{3}{|c|}{ Barton's SSSR** (1-10) } & \multicolumn{3}{|c|}{$\operatorname{LSSR}^{\wedge \wedge}$ (deg) } & Base++ $\varnothing$ & & & \\
\hline Sandstone & $6 \pm 1$ & 4 & 7 & $14 \pm 6$ & 8 & 22 & 32 & & & \\
\hline Sandy shale & $4 \pm 1$ & 3 & 5 & $4 \pm 3$ & 0 & 6 & 29 & & & \\
\hline Carb. shale ${ }^{\wedge}$ & $3 \pm 1$ & 2 & 4 & $4 \pm 3$ & 0 & 12 & 26 & & & \\
\hline Coal & $3 \pm 1$ & 2 & 6 & $4 \pm 3$ & 0 & 12 & 22 & & & \\
\hline \multicolumn{11}{|c|}{ Bedding planes } \\
\hline Sandstone & $6 \pm 1$ & 6 & 7 & $10 \pm 7$ & 1 & 22 & 30 & & & \\
\hline Sandy shale & $3 \pm 1$ & 2 & 3 & $6 \pm 3$ & 1 & 8 & 28 & & & \\
\hline Carb. shale ${ }^{\wedge}$ & $3 \pm 1$ & 3 & 4 & $6 \pm 3$ & 3 & 12 & 24 & & & \\
\hline Coal & $3 \pm 1$ & 2 & 5 & $6 \pm 3$ & 1 & 22 & 20 & & & \\
\hline
\end{tabular}

$(*)$ RM - Rock mass; (+) Statistics for normal frequency distribution mean \pm 1 standard deviation; (^) Carbonaceous shale; $(* *)$ SSSR - Small scale surface roughness (as observed over $100 \mathrm{~mm}$ defect trace length); $\left(\wedge^{\wedge}\right)$ LSSR - Large scale surface roughness (i.e. major surface undulations along entire defect trace length, stated in degrees); (++) Base friction angle stated in degrees. 
Table 4 Case study: models for intact rock UCS, density and RMR index

\begin{tabular}{llll}
\hline & Intact rock UCS strength & Intact rock density & $\begin{array}{c}\text { Bieniawski (1989) RMR } \\
\text { Index }\end{array}$ \\
\hline Sandstone & $28 \pm 13 \mathrm{MPa}$ & $24 \mathrm{kN} / \mathrm{m}^{3}\left(2.4 \mathrm{t} / \mathrm{m}^{3}\right)$ & $83 \pm 3$ \\
Sandy shale & $41 \pm 17 \mathrm{MPa}$ & $25 \mathrm{kN} / \mathrm{m}^{3}\left(2.5 \mathrm{t} / \mathrm{m}^{3}\right)$ & $79 \pm 6$ \\
Carbonaceous shale & $25 \pm 11 \mathrm{MPa}$ & $20 \mathrm{kN} / \mathrm{m}^{3}\left(2.0 \mathrm{t} / \mathrm{m}^{3}\right)$ & $75 \pm 7$ \\
Coal & $9 \pm 5 \mathrm{MPa}$ & $16 \mathrm{kN} / \mathrm{m}^{3}\left(1.6 \mathrm{t} / \mathrm{m}^{3}\right)$ & $38 \pm 4$ \\
\hline
\end{tabular}

Table 5 Case study: stratigraphic thickness and rock type composition in failure path domains

\begin{tabular}{lccc}
\hline \multirow{2}{*}{ Rock type } & \multicolumn{3}{c}{ Relative proportions of rock types } \\
& Case study slope: failure-path domain \\
& Upper & Central & Lower \\
\hline Sandstone & 0.417 & 0.333 & 0.450 \\
Sandy shale & 0.417 & 0.275 & 0.300 \\
Carbonaceous shale & 0.116 & 0.125 & 0.050 \\
\hline Coal seams & 0.050 & 0.267 & 0.200 \\
\hline Strata vertical thickness $(\mathrm{m})$ & 60 & 120 & 20 \\
\hline
\end{tabular}

Sedimentary strata comprised a cyclic repetition of sandstone, shale, siltstone, claystone, coal and various laminated mixes of the primary sedimentary rock types.

Bedding planes were relatively flat in most areas. There were three significant joint sets; these were orientated orthogonal to the bedding. Three other very minor sets were at few sparse locations.

Normal faults occurred at various locations. But, there was no evidence of thrust-faulting and zones of co-aligned but less continuous defects that often characterise ground conditions in many Australian coal mines.

Table 3 presents statistical models for bedding plane and joint set lengths, spacing, probability of cut-off by other defects; their large scale undulations (degrees) and small surface roughness (Barton 1-10) characteristics; and the length of 'bridges' between non cut-off defects. This data is collated for each major rock type that the writer examined.

Table 4 presents statistical models for intact rock UCS and RMR-index rating for each rock type. Indicative rock densities are also included.

The new $200 \mathrm{~m}$ high rock slope was being proposed in the part of lease that had not been previously mined. As shown in Figure 9(a) and right-hand bottom of Table 5, the writer partitioned the target slope into three stability analyses and Slip-Circle failure-path domains:

- Upper domain (60 m thick) where the slip-circle path would generally co-align with near-vertical joints.

- Central domain (120 m thick) where the slip-circle path would generally trend across near-horizontal bedding planes and near-vertical joints.

- Lower domain (40 m thick) where the slip-circle path would generally co-align with near-horizontal bedding planes. 
Table 5 documents the rock type composition of the three failure-path domains. This data was used to develop a weighted average strength model for intact rock in each domain.

\section{Case study Simplified Step-Path method strength results}

Figure 10 shows examples of Simplified Step-Path method derived shear strength models for bedding planes, joints, Hoek-Brown rock mass and Step-Path traverses.

A model similar to Figure 10(d) was developed for each rock type.

A weighted-average approach, based on relative occurrences of rock types, was used to develop Hoek-Brown and Step-Path shear strength models for each failure-path domain (upper, central and lower).

Figure 11 shows the averaged-weighted (by the relative proportion of each rock type in the strata) strength models developed for the various Slip-Path domains (i.e. entire slope, Upper, Central, Lower) in the case study slope.

Figure 11(a) shows that by considering weighted average (i.e. by relative proportion of each rock type in the strata), even the Hoek-Brown shear strength model can vary by up to 15 to $20 \%$ at different locations in the rock slope; justifying the statistical weighted-average analysis effort.

Figure 11 (d) shows that weighted average (i.e. by relative proportion of each rock type in the strata) bedding plane controlled failure path in the Lower Domain and vertical joint controlled failure path in the Upper Domain are 28 and 13\%, respectively, less strong (at $2 \mathrm{MPa}$ normal stress) than the Hoek-Brown failure path in the Central Domain.

Figure 11(d) mean shear strength models were input to conventional 2D limit-equilibrium slope stability analyses to determine overall slope angles and degree of dewatering necessary to achieve the agreed design Factor of Safety (FS).

\section{Conclusion}

The original STEPSIM and 1997-revised STEPSIM4 Step-Path methods are introduced for completeness of discussion. An easier to use SSPM is advocated for estimating the shear strength. However, statistical variability for all SSPM input parameters needs to be approximated by normal distributions.

Concepts of intact rock and rock mass anisotropy, Rosenblueth method of statistical moments and the use of Sampling Theory to adjust standard deviations are presented.

Whilst a statistical approach to rock mass characterisation is recommended, geotechnical stability analysts should not be blinded by fancy statistics to an extent that they lose sight of a sobering reality better known as the 'weakest link theory'. If critical failure paths exist at slope toe where stratigraphy comprises several rock types, including some very low strength varieties such as claystone, carbonaceous mudstone or worse, then there may be little merit in developing a weighted-average strength model based on relative proportions of all rock types occurring in the toe region. At this toe location, the critical failure path is not only likely to be relatively flat (i.e. sub-parallel to bedding), but also likely to traverse along the weakest rock type materials. These 'weakest-link' materials should be adopted for slope design, not some stronger weighted average values.

The case study is based on a multi-seam Asian coal mine. The sedimentary stratigraphy is cyclically repetitive. Statistical geotechnical models which were developed on actual field and laboratory data are tabulated.

Ground conditions in the case study area are similar to those seen at many other coal mines. But, the apparent absence of low-angle thrust-faults and swarms of similarly orientated shorter defects makes the case study conditions significantly better than those often observed in Australian coal mines. 
This paper shows that when bedding planes and subvertical joints are considered, the Step-Path estimated shear strengths for some rock types may be as high as $30-45 \%$ less than corresponding Hoek-Brown strength. This observation is similar to the writer's previous conclusions for other slope examples (Baczynski 2016). However, the average shear strength difference between weighted-average (i.e. by relative proportion of each rock type in the strata) failure paths in the three domains (Upper, Central and Lower) in the case study slope is $\pm 20 \%$, a less impressive difference. Step-Path strength is associated with $40 \%$ of the overall failure path length; Hoek-Brown strength with $60 \%$. Hence, in this particular case study, Step-Path considerations only reduce the overall failure path shear strength by about $8 \%$. Even this seemingly minor strength decrease reduces a slope FS of 1.3 to near 1.2 .

\section{References}

Baczynski, NRP 2000, 'STEPSIM4 Step-Path method for slope risks', in GeoEng 2000: International Conference on Geotechnical and Geological Engineering, Melbourne, Australia, Vol. 2, p. 86.

Baczynski, NRP 2001, 'Intact rock strength of Neranleigh-Fernvale strata', Australian Geomechanics, Volume on Geotechnical Engineering \& Engineering Geology of Brisbane and SE Queensland, IEAust, vol. 36, no. 3, pp. 9-15.

Baczynski, NRP 2016, 'Step-path method: impact of defect occurrence, cut-off and length on shear strength in rock slopes', in PM Dight (ed.), Proceedings of the First Asia Pacific Slope Stability in Mining Conference, Australian Centre for Geomechanics, Perth, in press.

Baczynski, N, Marples, R, Tamplin, S \& Choros, E 2001, 'Application of slope stability risk design process to open cut mines', R Doyle \& J Moloney (eds), in Geological Hazards - The Impact on Coal Mining, Coalfield Geology Council of New South Wales and New South Wales Department of Mineral Resources, pp. 151-171.

Barton, N 1976, 'The shear strength of rock and rock joints', International Journal of Rock Mechanics and Mining Sciences \& Geomechanics Abstracts, vol. 13, pp. 1-24.

Bieniawski, ZT 1989, 'Engineering rock mass classifications', John Wiley \& Sons, p. 251.

Carvalho, JL, Carter, TG \& Diederichs, MS 2007, 'An approach for prediction of strength and post yield behaviour for rock masses of low intact strength', in Rock Mechanics: Meeting Society's Challenges and Demands, pp. 249-257.

Hoek, E \& Brown, ET 1980a, 'Empirical strength criterion for rock masses', Journal of the Geotechnical Engineering Division, ASCE, vol. 106, no. GT9, pp. 1013-1035.

Hoek, E \& Brown, ET 1980b, Underground Excavations in Rock, London Institution of Mining and Metallurgy.

Little, LN, Cortes, JP \& Baczynski, NR 1999, Risk-based slope design optimisation study for the Ok Tedi copper-gold mine: Volume 5 : Geotechnical models and failure modes, Internal Report dated 30 Aug 1999, Ok Tedi Mining Limited, Mine Technical Services Department, Geotechnical Engineering Section, p. 108 \& Appendices A to F.

McMahon, BK 1971, 'Statistical methods for the design of rock slopes', in Proceedings of First Australia-New Zealand Conference on Geomechanics', vol. 1, pp. 314-321.

McMahon, BK 1974, 'Design of rock slopes against sliding on pre-existing fractures', in Proceedings 3rd Congress of the International Society for Rock Mechanics, National Academy of Sciences, Washington DC, vol. IIB, pp. 803-808.

McMahon, BK 1979, 'Report to Bougainville Copper Limited on slope design studies, Pan Hill', McMahon Burgess \& Yates, Sydney, internal report.

Read, JRL \& Lye, GN 1983, 'Pit slope design methods, Bougainville Copper Limited open cut', in Proceedings of the 5th Congress of the International Society for Rock Mechanics, Rotterdam, Balkema, Melbourne, vol. 1, pp. C93-C98.

Rosenblueth, E 1975, 'Point estimates for probability moments', in Proceedings of the National Academy of Sciences, vol. 72, no. 10 , pp. 3812-3814.

Rosenblueth, E 1981, 'Two-point estimates in probabilities', Applied Mathematical Modelling, vol. 5, no. 2, pp. 329-335. 